\title{
Composing Effective Teams through Team Dating
}

\author{
Petru L. Curșeu, Patrick Kenis, Jörg Raab and Ulrik Brandes
}

Petru L. Curşeu Tilburg University, The Netherlands

Patrick Kenis Antwerp Management School, Belgium

Jörg Raab

Tilburg University, The Netherlands

Ulrik Brandes

University of

Konstanz, Germany

\begin{abstract}
Previous research showed that short initial interaction in dyads accurately predicts future relation development. The paper extends these results from dyads to teams and demonstrates that data collected from short initial contacts (reciprocal relational preferences) are a sound basis for designing effective teams. In the approach we propose, potential team members have short initial contacts (popularly known as 'speed dating') and we use the information on interpersonal evaluations to create teams by maximizing the number of reciprocal relational preferences within a team. In a sample of 76 teams $(\mathrm{N}=378,36$ attribute-based teams and 40 team-dating teams), we show that teams formed based on relational data are more effective than teams formed by maximizing within team diversity (gender and nationality). Team-dating teams show a better teamwork quality and develop more complex collective knowledge structures compared with attribute-based teams.
\end{abstract}

Keywords: group cognitive complexity, team dating, team design, team diversity, teamwork

\section{Introduction}

Very often, the knowledge-intensive work in contemporary organizations is delegated to teams (Benders et al. 2002; Devine et al. 1999; Reagans and Zuckerman 2001; Strang and Jung 2009; Vera and Crossan 2004). The rationale behind this is that teams integrate various individual knowledges into collective knowledge (Curşeu et al. 2008; Okhuysen and Eisenhardt 2002; Zárraga and Bonache 2005), leading to higher quality decisions and solutions (Harrison and Klein 2007; Hinsz et al. 1997). However, there is a discrepancy between the prevalence of teams in organizational life and our knowledge about the way in which they have to be composed in order to be effective. Despite the fact that teams have received considerable scholarly attention during the last two decades and our knowledge and understanding of team processes as well as team outcomes have substantially grown (Devine et al. 1999; Marks et al. 2001; Ilgen et al. 2005), the question of how to form effective teams remains largely unanswered (Hodgkinson and Healey 2008).

Studies of work teams showed that teamwork quality and team effectiveness are influenced by a variety of factors from group characteristics and resource availability to factors related to organizational context (Hackman 1990; Hoegl and Gemuenden 2001; Stewart 2006), and recent studies acknowledged the crucial role of human and social capital for team effectiveness (Ilgen et al. 2005; Katz et al. 2004; Oh et al. 2004; Reagans et al. 2004). For the particular case of 
knowledge-intensive tasks, team success is dependent on the resources made available to the team through the qualities and attributes of the individual team members (team human capital) (Carroll et al. 2006; Harrison and Klein 2007), but also through the team members' social relationships within the team as well as outside the team (team social capital) (Oh et al. 2004; Reagans and Zuckerman 2001). So far the team design literature has mainly focused on design propositions inspired by the team composition literature trying to optimize team human capital (Hodgkinson and Healey 2008; Stewart 2006). Because the nature and structure of social relations (team social capital) are highly relevant for team effectiveness as well, they should also inform the team design propositions in order to maximize the likelihood of sound team design principles (Jelinek et al. 2008; Romme 2003).

In terms of practical relevance, although data on team members' relations (network data) is potentially valuable in team formation (Reagans et al. 2004), it is still rather difficult to use network analytic techniques to collect full scale data in real organizational settings and more parsimonious methods are needed in order to fully use the potential of network data in team formation. Therefore, the aim of our study is to combine the insights from team diversity literature and social network research to come up with viable practical suggestions for effective team design. As a consequence, we introduce and subsequently test a new team design strategy based on network data, called 'team dating', and explore the role of reciprocal relational preferences expressed after short initial contacts on teamwork quality and group cognitive complexity.

We hereby extend existing research in the following ways. First, we use a matching procedure, popularly known as speed dating, and a mathematical framework that generalizes pair matching based on initial contacts from dyads to teams, as a team composition method. This adds to the team design literature, in which relational preferences have been implicitly used in the so-called 'self-selection' strategy for team formation, but no previous attempt was made to use the direct as well as the indirect ties in a network clustering algorithm as a basis for team design. Therefore, the study contributes to the team design literature by testing the design proposition that reciprocated relational preferences expressed by participants can be used for designing effective teams. Second, by using social network theory concepts and methods, the study investigates the generalizability of first-impression theory predictions from dyads to the team level and thus provides a first building block of a micro-foundation, why teams that are formed on the basis of relational data might be more effective. Finally, the study connects the social networks literature with the literature on team processes and emergent states. Team processes and emergent states evolved as a rather independent area of study within the systemic approaches to teams and teamwork and so far there is little to no empirical evidence connecting this stream of literature with the developments in the literature on social networks. Rather than focusing on already existing within group ties (as is the case in most of the studies on networks and teams), we test the impact of ex-ante reciprocated relational preferences for future team members on team processes and emergent states. 


\section{Theory and Hypothesis}

The team diversity literature is probably the most comprehensive stream of literature that explored the implications of human capital for team effectiveness (Hodgkinson and Healey 2008). There is, however, a lack of consensus in the team diversity literature as to which of the individual team members' attributes are beneficial and which are disruptive for teamwork and team effectiveness (Hodgkinson and Healey 2008; Van Knippenberg et al. 2004). A recent taxonomy of team diversity introduced by Harrison and Klein (2007) emphasizes that attributes creating disparity or separation are disruptive for teamwork and team effectiveness, and attributes that create informational variety are beneficial for innovation, creativity and decision quality in teams. Team variety refers to the differences in type, source or category of relevant knowledge or experience among group members and therefore reflects a horizontal differentiation within teams that fosters creativity and innovation and increases decision quality in teams.

However, a team is effective in knowledge intensive tasks only to the extent to which it is able to successfully integrate the individual knowledge of its members (this process was labelled as knowledge integration by Okhuysen and Eisenhardt (2002), as the elaboration of task information by Van Knippenberg et al. (2004), or group cognitive complexity by Curşeu et al. (2007)). In this paper, we will use the term team cognitive complexity to define the richness of the collective knowledge structures that emerge as a team level phenomenon from the integration of individual specialized knowledge through interpersonal interactions. The knowledge integration process and the emergent team cognitive complexity are therefore essential indicators of team effectiveness in knowledge intensive tasks (Bogenrieder and Nooteboom 2004; Curşeu 2006; Curşeu et al. 2007, 2008; Hinsz et al. 1997; Okhuysen and Eisenhardt 2002; Strang and Jung 2009). A central argument in team cognition research is that knowledge integration in teams depends on the quality of interpersonal relations established among team members (Rentsch and Woehr 2004; Curşeu et al. 2008), a proposition that recently received empirical support (Curşeu et al. 2007, 2010). This is also in line with a general claim in the social network literature, namely that relationships are critical for acquiring information to be used for any kind of problem solving, be it on the individual or the group level. To summarize, next to team variety, the quality of interpersonal relations established among team members is an essential driver for team effectiveness. Effective team design strategies should therefore focus not only on the allocation of the human capital in teams (classic HR perspective), but also on the quality of interpersonal relationships within teams (a social capital approach) (Hodgkinson and Healey 2008; Minssen 2005).

In the social network literature a team is conceptualized as an emergent phenomenon described as a subset of fully connected nodes on at least one type of tie (Katz et al. 2004). Cummings and Cross (2003) showed that distinct hierarchical structures, structural holes of the leader and a distinct core-periphery structure were negatively associated with team performance in non-routine complex tasks. Moreover, the internal social network structure is a possible mechanism intervening between team composition and its performance (Reagans and Zuckerman 
2001; Reagans et al. 2004). Trying to link team demography and internal as well as external social network characteristics with team performance, Reagans et al. (2004) tested a model in which the high demographic diversity of a team increases team performance by decreasing the internal network density and by increasing the external network range. The empirical results collected in an R\&D firm from 113 employees involved in several project teams supported this model in which team diversity and specific network characteristics are closely linked, and dense internal networks are beneficial for team performance.

Using network data to manage teams, however, is a difficult enterprise. First, it seems that empirical data concerning the impact of internal network density on performance are equivocal. Second, although the internal network structure seems to be a mediating variable for team performance (Reagans and Zuckerman 2001; Reagans et al. 2004), the factors causing the emergence of tie patterns, which improve team performance, are not yet fully understood (Katz et al. 2004). Finally, most of the managers are not aware of the external network ties of their subordinates which makes using external network data to design effective teams difficult (Reagans et al. 2004). The main question is, therefore, how to collect reliable network data that are correlated with high teamwork quality and use them for team design.

We propose a shift in focus from using network data about the previous internal or external network structure of the team (which in the case of newly formed teams might be unavailable) to using relational data collected from short initial contacts among the potential team members. We argue that these data are accurate predictors for the development of interpersonal relationships within teams and, because these relationships are seen as being crucial for teamwork and team effectiveness (Marks et al. 2001; Ilgen et al. 2005), these network data can be successfully used to form effective teams.

In a simulation experiment, Krackhardt and Stern (1988) used an organization game to explore the impact of friendship ties manipulation on organizational performance. The authors grouped the participants in two hypothetical organizations based on the distribution of their friendship ties. The first organization was created in a way that minimized the occurrence of friendship ties within the organization and maximized the ones between the two organizations, while the second organization was created in a way that maximized the occurrence of friendship ties within organization at the expense of friendship ties between organizations. Four indicators of organizational effectiveness evaluated at the end of the last round of the simulation game, showed that organizations based on minimizing friendship ties outperformed the organizations based on maximizing friendship ties within their boundaries. Krackhardt and Stern (1988) argue that these results reflect a lock-in effect in naturally occurring groups (created by maximizing the incidence of friendship ties). However, more recent research (Hinds et al. 2000) shows that when using more instrumental types of ties (collaboration in a work-related project) the ex-ante reciprocated preferences may have beneficial effects on teamwork.

In a similar vein, the literature on group member familiarity shows that groups whose members have strong interpersonal ties (friendship ties) outperform groups whose members develop weak interpersonal ties (acquaintances) (Shah 
and Jehn 1993; Jehn and Shah 1997; Okhuysen and Eisenhardt 2002). Moreover, Karau and Williams (1993) show in a meta-analytical study on social loafing that the chance of engaging in social loafing is lower for groups of friends than for groups of strangers. Therefore, results reported in the literature remain split about the relationship between friendship ties and team outcomes. Pre-existing friendship ties seem to have no effect or be detrimental for team functioning, while strong ties developed within groups upon task-related interactions seem to have both socio-emotional (increase the quality of teamwork) as well as cognitive benefits (foster creativity and learning) for team functioning. The question is, therefore, how can one predict the emergence of strong within-group interpersonal ties? This points to the importance of first impression formation.

Studies on impression formation have shown the strong and persistent effect of the first impression on the quality of the future relationship (Jones 1990; Ambady and Rosenthal 1992). A positive first impression is likely to trigger positive evaluations in future encounters and therefore strengthen the interpersonal relationship. In contrast, a negative first impression is very difficult to change even if sound counterarguments are provided later on, having therefore a negative impact on relationship development (Fiske and Taylor 1991). Also, experimental research on impression formation shows that the first adjectives presented in a profile list have a stronger effect on the personality impression than the later ones (Asch 1946). From a cognitive perspective, these findings have been explained as results of the primacy effect. The primacy effect refers to the enhanced sensitivity of the human cognitive system to the information placed at the beginning of a series to be remembered (Stewart 1965).

In the first impression field, a recent area of research concerns the accuracy of predictions for personal characteristics based on 'thin slices' of expressive behavior (Ambady and Rosenthal 1992, 1993; Borkenau et al. 2004). In this line of research several empirical studies showed that, based on very short initial interactions (from 30 seconds up to $4-5$ minutes), people can accurately predict others' personality characteristics and intelligence (Borkenau et al. 2004) and their sexual orientation (Ambady et al. 1999), and students can accurately predict subsequent teacher evaluations (Ambady and Rosenthal 1993). An extensive meta-analysis on the 'thin slices' literature carried out by Ambady and Rosenthal (1992) showed that people make accurate predictions about a wide range of social behaviors, interpersonal expectancies and biases (e.g. voting behavior, detection of deception in a relationship, future relationship development) after very short interactions (about 30 seconds), and increasing the length of the initial interaction up to 5 minutes does not significantly improve the accuracy of the predictions (Ambady and Rosenthal 1992).

A more specific investigation on the effect of the first impression on relationship development was recently carried out by Sunnafrank and Ramirez (2004). The authors asked students at the beginning of the academic year to make predictions about the later development of their relationships with several others based on a very short interaction (between 3 and 10 minutes). The results showed that the evaluations developed during initial conversations successfully predicted the long-term development of interpersonal relationships (Sunnafrank and Ramirez 2004). By extrapolating these results from dyads to groups, we 
argue that reciprocated relational preferences are beneficial for the teamwork quality. Our first hypothesis is:

Hypothesis 1. Teamwork quality is higher in teams based on maximizing the number of reciprocal relational preferences than in attribute-based teams.

Other previous studies that explored ways of managing group diversity and fostering the positive outcomes of group diversity (their higher creative potential and larger pool of knowledge, abilities and skills, which are decisive for accomplishing complex tasks) identified interpersonal congruence as a crucial mediating factor (Polzer et al. 2002; Swann et al. 2004). Interpersonal congruence refers to the similarity between a person's self-view and others' appraisal of that person (Polzer et al. 2002). Initial appraisals after a ten-minute introduction contributed to varying levels of congruence within teams, and this congruence moderated the effect of diversity on team outcomes four months later, in the sense that diversity had a negative effect in low-congruence groups and a positive effect in high-congruence groups on creative task performance as well as on the social integration of the group and group identification. High interpersonal congruence resulting from a self-verification effect (targets bringing perceivers' appraisals into line with their self-views) also improves the effectiveness of team processes (increases social integration and identification with the group and reduces relationship conflict) (Swann et al. 2000). Moreover, the study by Swann et al. (2003) shows that individuation (recognizing someone as a distinct individual) promotes self-verification effects and ultimately leads to a higher identification with the group and higher creativity. As argued before, reciprocated relational preferences are expected to indicate positive interpersonal evaluations and thus foster individuation effects in groups. The more group members individuate each other, the higher the chance of self-verification processes (Swann et al. 2003) and the lower the chance of social loafing (Karau and Williams 1993), which will ultimately lead to a better knowledge integration in teams (Curseu et al. 2010; Okhuysen and Eisenhardt 2002).

To summarize, maximizing reciprocal relational preferences within groups increases the chances of individuation and task participation of the group members and thus increases the elaboration of task-relevant information or the cognitive complexity of groups. The second hypothesis of this study therefore is:

Hypothesis 2. Team cognitive complexity is higher in teams based on maximizing the number of reciprocal relational preferences than in attribute-based teams.

\section{Methods}

\section{Sample and procedure}

The participants, 378 students (153 women) from Tilburg University, were distributed into 76 teams having four to six members. The teams were involved in two different courses, involving similar educational activities, and they were required to deliver a final team product (e.g. research project) at the end of the semester. From the total number of teams, $36(\mathrm{~N}=194)$ attended the first course 
and were created by assigning the students to a team based on their gender and nationality, while 40 teams $(N=184)$ attended the second course and were created on the basis of their expressed preferences in a speed-dating session. During a seven week period, all teams participated in several team activities during class (e.g. case analyses, discussion forums) or while working on the final project. Group level data were collected from these teams by using a team questionnaire and a conceptual mapping technique. The aim of this technique is to investigate the level of cognitive complexity of teams in relation to a specific conceptual domain. In the same meeting a questionnaire was handed out and the teams were asked to fill in the questionnaire by consensus.

\section{Independent variable}

The independent variable in this study is the team formation strategy with two conditions: attribute-based teams and team-dating teams. Attribute-based teams were created by maximizing gender and nationality diversity within each team. The reasoning behind this strategy is that increasing team diversity increases the elaboration of task-relevant information by bringing in different perspectives and will ultimately increase team performance in a complex knowledge production task (Hambrick et al. 1998; Harrison and Klein 2007). The diversity index was computed using a formula proposed by Teachman (1980), widely used in the team diversity literature (Williams and Meân 2004) and illustrative for the conceptualization of diversity as variety (Harrison and Klein 2007). The theoretical maximum for the diversity index $(\mathrm{H})$ depends on the total number of categories within a group (Williams and Meân 2004). Since both types of diversity are expressed as dichotomous variables (gender: women and men, nationality: Dutch and non-Dutch), we only had two categories in our formula. The higher the values of the $\mathrm{H}$ index, the higher the team's diversity. For teams consisting of only one category, $\mathrm{H}=0$.

To create the teams in the second condition (team-dating teams) a speed-dating session was organized. Because the students were involved in a course, the speed-dating session was performed at the beginning of the semester. The 184 students self-enrolled in six different subgroups based on their preferences for the lecture time schedule. A speed-dating session was held for each of these six subgroups. During this session each student had to interact for a short period of time (two minutes) with every other student in the subgroup. The interaction sequences were planned to optimize the time (to have as many simultaneous pair interactions as possible per time unit). The room was setup in a way that the partner changes were carried out as quickly as possible. Thirty seconds were granted for the partner change after each discussion round.

In the room, 17 locations were defined and each location was occupied by a speed-dating pair. The students were free to choose the subject of the conversation. To structure the process, the round number was announced before every new conversation between two students. Each student was provided with a table specifying the location in which he/she was supposed to be for each round and the partner he/she was supposed to meet there. In the last column of the table the students were instructed to write their decision about the discussion partner (their willingness to share the same team with a certain speed-dating partner). In 
Figure 1.

The results of the individual preferences for others expressed during the team dating session (in the network, the marked clusters are the teams; 18 is a missing value) the instructions it was specified that a maximum of eight students could be chosen as preferred teammates. These expressed preferences produced a network with reciprocated and non-reciprocated choices.

A network clustering algorithm was then used to group the students into teams, subject to the constraint that each team must have five or six members. Reciprocated ties were given twice the weight of non-reciprocated ones, so that clusters (i.e. groups) should cover maximum weight. Optimal clustering thus corresponds to satisfying as many preferences as possible, but is computationally intractable in this and reasonably related scenarios (see, e.g., Gaertler 2005 for an overview). Given the nature of our data, however, most advanced clustering algorithms will efficiently yield sufficiently good solutions. Here, we used the network clustering approach introduced in Brandes et al. (2003) with subsequent manual inspection and minor rearrangements. See Figure 1 for an example.

Because the two courses were scheduled in the first study unit, we estimate that the likelihood of pre-existing ties within the two subsamples is relatively equal. Moreover, as shown by Hinds et al. (2000), the pre-existing ties are not very good predictors of preference for future team mates. Students use competencerelated cues when they make a choice for future team mates.

\section{Dependent variables}

The dependent variables used in this study are teamwork quality and teams'cognitive complexity. Teamwork quality is a multifaceted concept (see for a theoretical

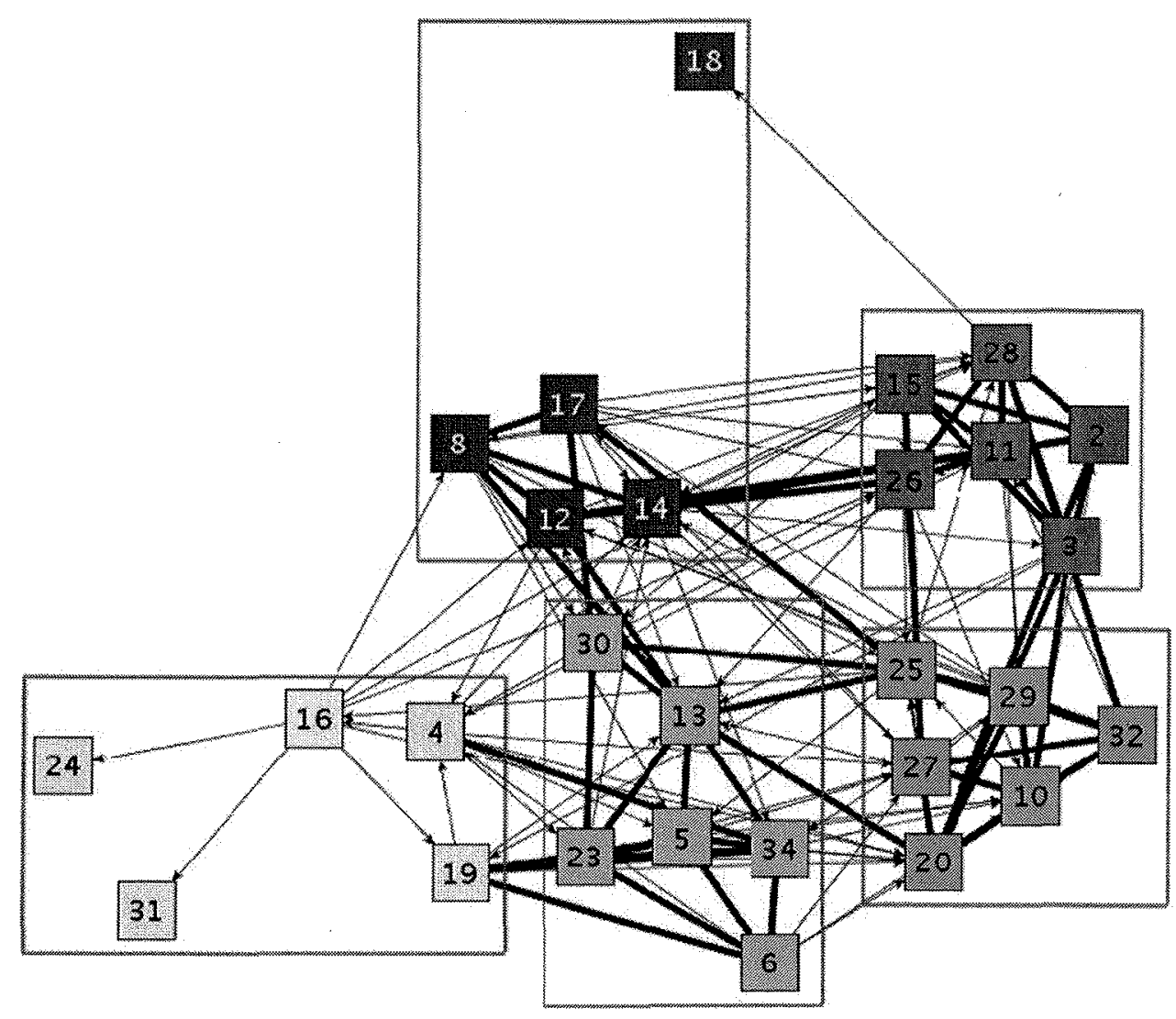


discussion Hoegl and Gemuenden 2001) and includes team process measures (communication, coordination and planning) as well as emergent states (cohesion and team potency). Teams' cognitive complexity was used as an objective measure of the elaboration of task-relevant information (Curşeu et al. 2007). Since groups have been involved in a knowledge-creation task, cognitive complexity is crucial for team performance in this type of task and it will be an objective measure of team outcomes (Curşeu et al. 2010).

\section{Teamwork quality}

Each team was asked to fill in a group questionnaire evaluating group processes and emergent states. The team members were instructed to discuss every item of the questionnaire and agree upon a value that best described their team. Therefore, the data were collected at the group level. The group consensus method is superior to the conventional technique of aggregating individual responses in the sense that it has a better predictive validity and it satisfies better the requirements for collecting and analyzing team-level data (Bar-Tal 1990; Kirkman et al. 2001). The answers were recorded on a five-point Likert scale whose anchors were adapted to the content of each item $(1=$ completely disagree to $5=\mathrm{com}$ pletely agree). For every variable the final score was computed by adding the partial item scores.

Team processes refer to the interdependent actions of team members that lead to task performance (Marks et al. 2001) and three team processes were evaluated in this study: planning, coordination and communication. Planning refers to the process of dividing the general team task into sub-tasks and distributing them among the team members, developing a specific strategy to deal with the task, as well as clarifying the goals and general objectives of the team (Eby et al. 1999). Planning was evaluated in the present study by five items developed by Eby et al. (1999) (e.g. 'The team has developed its own strategy in approaching this project'. Coordination reflects the synchronization of the team members' actions and the progressive evaluation of the way in which these specific integrative activities are being done (Eby et al. 1999)). To evaluate coordination we selected five items developed by Eby et al. (1999) based on their reported factor loadings (e.g. 'The team members have monitored each other's activity during the task'). Communication is the process of giving and receiving feedback among team members (Eby et al. 1999). The four items evaluating communication in the group questionnaire were selected based on their reported factor loading from Eby et al. (1999) (e.g. 'During the debates, each team member has been carefully listened to by the others'). The Cronbach's alpha for the 14 items used to evaluate team processes is 0.83 .

Emergent states are epiphenomena created by the social interactions among the team members that are dynamic in nature and depend on team inputs, processes and outputs (Curşeu 2006; Marks et al. 2001). Two of the most commonly cited emergent states are evaluated in this study: cohesion and potency. Cohesion is a 'dynamic process that is reflected in the tendency for a team to stick together and remain united in the pursuit of its instrumental objectives and/or for the satisfaction of members' affective needs' (Carron and Brawley 2000). 
The four items measuring cohesion were selected from the Group Environment Questionnaire developed by Carron et al. (1985). The items were initially developed to evaluate cohesion as a multidimensional construct in sports teams, but items adapted from this questionnaire have been used in many other contexts (Carron and Brawley 2000; Blanchard et al. 2000). For the present study, two items referring to group integration - task (e.g. 'Our team is united in trying to make high quality assignments') and three referring to group integration - social (e.g. 'The team members feel they belong to this team') were selected from Blanchard et al (2000) based on their reported factor loadings.

Potency refers to the team members' collective belief that the team can be effective (Guzzo et al. 1993; Gully et al. 2002) and in the present study was evaluated using five items selected from an eight-item questionnaire of potency developed by Guzzo et al. (1993) (e.g. 'This team believes it can be very productive'). In their empirical study Guzzo et al. (1993) showed that group potency is a measurable attribute, which can accurately predict group performance. The Cronbach's alpha for the 10 items used to evaluate the emergent states is 0.79 .

Although teamwork quality is multifaceted, previous empirical studies reported a one-factor solution for all facets of teamwork quality (see for details Eby et al. 1999; Hoegl and Gemuenden 2001). The results reported in this study are similar: team processes and the emergent states are highly correlated as shown by the results reported in Table 1 .

\section{Teams' cognitive complexity}

A cognitive mapping technique was used to evaluate the cognitive complexity (or the degree of elaboration of task-relevant information) of the teams. In a conceptual map, concepts are represented as nodes and the strings represent the links between these concepts (Bougon 1992). The complexity of the map is illustrative for the way in which an individual or a team understands a conceptual domain (Calori et al. 1994). To study the teams' cognitive complexity the 20 most relevant concepts for the studied domain were selected and used in the cognitive mapping session. A card-sorting technique was used for the conceptual mapping. Each team was presented with 20 cards on which the concepts were written and was asked to organize these concepts in a way that made sense to them. Then they were instructed to draw lines among these concepts and to specify on the connections the nature of the relation between concepts. Three indicators were used to evaluate the conceptual maps: map connectivity, diversity and complexity.

Conceptual map connectivity (CMC) refers to the total number of connections established between the concepts. Map diversity (CMD) was computed as the number of distinct types of relations established between the concepts. Starting from the taxonomy proposed by Gómez et al. (2000), we considered seven types of relations between concepts: causal (CA), association (ASO), equivalence (EQ), topological (TOP), structural (STR), chronological (CHR), and hierarchical (HIE) relations (Gómez et al. 2000). The CMD index could therefore take on a value between 1 and 7 . 
Conceptual map complexity ( $\mathrm{CMCo}$ ), on the other hand, was computed using the formula: $C M C_{0}=\frac{C M C \times C M D}{N o C}$ where NoC is the total number of concepts used in the map. This formula for computing groups' cognitive complexity was also used in a previous study by Curşeu et al. (2007) and it is derived from the definition provided by Calori et al. (1994): 'the complexity of an individual conceptual system is determined by two interdependent aspects: the number of parts or dimensions of the system and the nature and the extent of rules for integrating these parts' (Calori et al. 1994: 439). According to the formula used, the cognitive complexity for a team reflects the integrative complexity of a cognitive map - conceptualized as both the degree of differentiation and integration in the groups' knowledge structure.

A second indicator for the cognitive maps developed by the teams was the accuracy of these maps. In theory, it is possible that groups develop highly complex yet inaccurate knowledge representations. Therefore, two experts working together mapped the concepts and the two resulting expert maps were used to benchmark the maps developed by the groups (the complexity of the expert maps is 9.75 for the first course and 10 for the second one). Based on the complexity of the two expert maps, we can conclude that no differences due to the type of content are to be expected between the two conditions. Two independent coders, unaware of the hypotheses of this study, compared each group map with the corresponding expert map on three dimensions: (1) the extent to which the conceptual clusters used in the group map is similar with the ones presented in the expert map (a conceptual cluster is an association of 3-6 concepts which are tightly interconnected), (2) the extent to which the concepts used in the map are connected in similar ways as the ones presented in the expert map and (3) the extent to which the map has in general, a similar structure with the expert map.

To check for the consistency of the evaluations an intraclass correlation coefficient was computed to adjust actual agreement levels for agreement by chance. The resulting values are .92 for the first dimension (clusters), .90 for the second (connections) and .88 for the third (general similarity) when using an absolute agreement definition and average measurement since the two evaluations for the three dimensions were averaged afterwards to compute a general accuracy score. Therefore, as a general indicator of cognitive map accuracy we used the mean of the two evaluations for the three dimensions described before.

\section{Results}

Table 1 presents descriptive statistics and correlations among the variables. The bivariate associations presented in the correlation matrix indicate provisional support for both hypotheses.

We performed four hierarchical regression analyses in order to further test our hypotheses. In all the regressions, group size was entered as a control variable in the first step of the analysis. Further on, two operationalizations of group variety (nationality and gender variety) were entered in the second step of the analyses. Finally, team formation strategy was entered in the last step of the analysis and 
Table 1. Descriptive Statistics and Correlations at Team Level $(\mathrm{N}=76)$

\begin{tabular}{|c|c|c|c|c|c|c|c|c|c|c|c|c|}
\hline & Mean & $\mathrm{SD}$ & 1 & 2 & 3 & 4 & 5 & 6 & 7 & 8 & 9 & 10 \\
\hline 1. TFS & .52 & .50 & & & & & & & & & & \\
\hline 2. Group size & 4.97 & .90 & $-.43 * *$ & & & & & & & & & \\
\hline 3. Gender variety & .54 & .19 & -.01 & -.04 & & & & & & & & \\
\hline 4. Nationality variety & .08 & .18 & -.10 & .09 & -.05 & & & & & & & \\
\hline 5. Communication & 15.59 & 2.35 & $.35^{* *}$ & -.12 & -.02 & -.14 & & & & & & \\
\hline 6. Coordination & 20.42 & 2.77 & $.52^{* *}$ & -.21 & -.00 & .04 & $.44 * *$ & & & & & \\
\hline 7. Planning & 19.46 & 2.53 & $.38 * *$ & -.08 & .08 & .01 & $.38 * *$ & $.60^{* *}$ & & & & \\
\hline 8. Cohesion & 20.18 & 2.70 & $.36^{* * *}$ & $-.33^{* *}$ & -.07 & -.05 & $.24 *$ & $.44^{* *}$ & $.42 * *$ & & & \\
\hline 10. Team cognitive complexity & 3.55 & 2.41 & $.47 * *$ & -.06 & .12 & $.265^{*}$ & $.30^{* *}$ & $.32 * *$ & $.35^{* *}$ & $.24 *$ & $.30 * *$ & \\
\hline 11. CM accuracy & 40.32 & 20.48 & $.38 * *$ & $-.36^{* *}$ & .06 & .18 & .22 & $.28^{*}$ & $.24^{*}$ & $.26^{*}$ & $.28^{*}$ & $.56^{* *}$ \\
\hline
\end{tabular}

Note: ${ }^{* *}$ - correlation is significant at the 0.01 level ( 2 -tailed), and * - correlation is significant at the 0.05 level (2-tailed), CM - cognitive map, TFS - team formation strategy is a dummy variable with 1 team dating teams and 0 attribute-based teams. 
it was coded as a dummy variable with team-dating teams coded as 1 and attribute-based teams coded as 0 . The results of the regression analyses are presented in Table 2. Variance inflation factors (VIF) were used to check for multicollinearity, and because all VIF scores are below 1.24 we can conclude that multicollinearity was not a serious problem in the analyses.

The first hypothesis stating that team-dating teams will experience higher levels of teamwork quality as compared to attribute-based teams is fully supported. Team-dating teams enact more effective teamwork processes $(\beta=.55, \mathrm{p}<.0001)$ and report higher scores for the emergent states $(\beta=.37, p<.003)$ than the attribute-based teams (see Model 3 in Table 2). Our second hypothesis is also supported and our results show that, in cognitive terms, team-dating teams develop more complex $(\beta=.58, p<.0001)$ and more accurate cognitive maps $(\beta=.30, p<.009)$ than attribute-based teams (see Model 3 in Table 3 ).

None of the team variety variables has a significant impact on the two dimensions of teamwork quality. However, as hypothesized by Harrison and Klein (2007), we found a positive significant impact of nationality variety on team cognitive complexity $(\beta=.32, \mathrm{p}<.001)$ as well as a positive and significant

Table 2.

The Results of Regression Analyses for Team Processes and Emergent States
Table 3.

Results of

Regression Analyses for Team Cognitive Complexity and Cognitive Map Accuracy

\begin{tabular}{lccccccc}
\hline & \multicolumn{3}{c}{ Team processes } & & \multicolumn{3}{c}{ Emergent states } \\
\cline { 2 - 3 } \cline { 7 - 8 } Step / Predictors & Model1 & Model2 & Model3 & & Model1 & Model2 & Model3 \\
\hline 1. Group size & -.17 & -.17 & .06 & & $-.22^{* *}$ & $-.23^{* *}$ & -.07 \\
2. Gender variety & & .01 & .03 & & -.12 & -.11 \\
$\quad$ Nationality variety & & -.01 & .02 & & .05 & .08 \\
3. TFS & & & $.55^{* * *}$ & & & $.37^{* * *}$ \\
$\mathrm{R}^{2}$ & .03 & .03 & .28 & & .05 & .07 & .18 \\
Adjusted $\mathrm{R}^{2}$ & .01 & .008 & .24 & .03 & .03 & .13 \\
F change & 2.44 & .013 & $24.55^{* * *}$ & $3.98^{* *}$ & .76 & $9.81^{* * *}$ \\
\hline
\end{tabular}

Note: $\mathrm{N}=76,{ }^{*} \mathrm{p}<.10,{ }^{*} \mathrm{p}<.05, * * * \mathrm{p}<.01$, standardized regression coefficients are reported for the respective regression steps, TFS team formation strategy coded as a dummy variable with teams formed on the basis of team dating coded as 1 and attributes based teams coded as 0 , Team processes refer to the quality of communication, coordination and planning within teams and the emergent states are cohesion and potency.

\begin{tabular}{lccccccc}
\hline & \multicolumn{2}{c}{ Team cognitive complexity } & & \multicolumn{3}{c}{ CM accuracy } \\
\cline { 2 - 3 } \cline { 7 - 8 } \cline { 7 - 8 } Step / Predictors & Model1 & Model2 & Model3 & & Model1 & Model2 & Model3 \\
\hline 1. Group size & .02 & -.0 & .16 & & $-.36^{* * * *}$ & $-.38^{* * *}$ & $-.25^{*}$ \\
2. Gender variety & & .13 & .15 & & .06 & .06 \\
$\quad$ Nationality variety & & $-.28^{* *}$ & $.32^{* * *}$ & & & $.22^{* *}$ & $.24^{* *}$ \\
3. TFS & & & $.58^{* * *}$ & & & $.30^{* * *}$ \\
$\mathrm{R}^{2}$ & .004 & .09 & .37 & & .13 & .18 & .25 \\
Adjusted $\mathrm{R}^{2}$ & .00 & .05 & .33 & & .12 & .14 & .21 \\
F change & .31 & $-3.63^{* *}$ & $1.23^{* * *}$ & & $11.21^{* * *}$ & $2.25^{*}$ & $7.13^{* * *}$ \\
\hline
\end{tabular}

Note: $\mathrm{N}=76,{ }^{*} \mathrm{p}<.10,{ }^{* *} \mathrm{p}<.05,{ }^{* * *} \mathrm{p}<.01$, standardized regression coefficients are reported for the respective regression steps, TFS team formation strategy coded as a dummy variable with teams formed on the basis of team dating coded as 1 and attributes based teams coded as $0, \mathrm{CM}$ - cognitive map, $\mathrm{CC}-$ cognitive complexity. 
impact of nationality diversity on cognitive map accuracy $(\beta=.24, p<.02)$. Gender variety has also a positive yet not significant impact on both cognitive complexity $(\beta=.15, \mathrm{p}<.10)$ and on cognitive map accuracy $(\beta=.06, \mathrm{p}<.5)$. Therefore, our results partially support the claim that team variety is beneficial for the teams' cognitive complexity.

\section{Discussion}

The present study yields several important findings. First, this study shows that teamwork quality is better in teams based on reciprocal relational preferences expressed by potential team members after short initial contacts. It shows that relational data can be successfully used to design teams that experience higher teamwork quality. Second, the present study also shows that knowledge integration is more effective in team-dating teams than in attribute-based teams. Third, our findings also support the positive impact of team variety on teams' cognitive complexity. The impact of team diversity on the elaboration of taskrelevant information has been acknowledged several times as a main benefit of diversity (Williams and O'Reilly 1998, Van Knippenberg et al. 2004). However, as argued by Harrison and Klein (2007), only the horizontal differentiation within teams (variety) is expected to have a positive impact on teams' cognitive complexity. Our results support this line of reasoning and show that team diversity as variety is beneficial for teams' cognitive complexity.

This study contrasted two team design strategies: one based on maximizing within-team variety for a particular task in which team variety is supposed to positively influence performance and one based on relational data based on short interpersonal interactions. The effect of the independent variable (team design strategy) is significant both for teamwork quality and the cognitive variables evaluated as team effectiveness criteria in this study. Our results confirm that team processes are more effective in teams formed on the basis of relational data than in teams created on the basis of attribute data and that the former develop more complex representations related to the task at hand.

A possible explanation for the positive impact of team formation strategy on teamwork quality is the strong and pervasive effect of the first impression formation and cognitive social schema use (Jones 1990; Fiske and Taylor 1991). Very early in a relationship, people make predictions about the behavior of their peers and create expectations about the future development of a possible relationship, and often these predictions are accurate (Fiske and Taylor 1991; Ambady and Rosenthal 1992; Sunnafrank and Ramirez 2004). If the positive expectations are reciprocal, it is very likely that the quality of the future relationship will be very high and the way they will communicate within a team will be more effective, as our results show. The planning process is not exclusively dependent on social interactions but, within a team, the social interactions among team members are crucial since role assignments and action prioritization are essential parts of planning and strategy formulation (Marks et al. 2001).

Coordination is also an important process (an action process according to Marks et al. 2001) for task accomplishment through which individual contributions 
are integrated into a team outcome. Both team planning and coordination are closely related to communication (Eby et al. 1999; Marks et al. 2001) and, as the results of our study show, these processes are more effective in team-dating as compared to attribute-based teams. Many scholars have acknowledged the fact that a team's capability to perform in the future is an essential indicator of a team's effectiveness (Hackman 1990; Guzzo and Dickson 1996). Group potency refers to the shared belief of team members that the team can be effective across tasks and contexts (Guzzo et al. 1993; Gully et al. 2002), and it is significantly higher in groups formed on the basis of relational data than in groups formed on the basis of the attributes of their team members.

The results of our study show a moderate negative association between nationality and team formation strategy (team dating teams have a slightly lower nationality diversity as compared to attribute based teams), however the correlation is not statistically significant (see for details Table 1). These results are the opposite of what Krackhardt and Stern reported in their 1988 study; nevertheless, they are in line with the results reported by Hinds et al. (2000), showing that people rely more on indicators of competence and not on similarity when choosing future teammates. In general, results concerning team effectiveness cannot be generalized across types of ties. Krackhardt and Stern (1988) focused on friendship ties, while in the present study we used the relational preferences, which as shown by Hinds et al. (2000) can be determined by other criteria when the expected outcome is the creation of a team with a specific task.

Concerning the second dependent variable (teams' cognitive complexity), the team-dating strategy seems to also lead to better results. Team-dating teams had a higher cognitive complexity than attribute-based teams. Cognitive complexity is a functional aspect, which can be understood as a continuum with cognitive simplicity at one end and cognitive complexity at the other. High cognitive complexity refers to an information-processing style defined by the use of many interrelated constructs (Curşeu et al. 2007). The ability to process several dimensions in a conceptual domain results in the development of connections among the differentiated characteristics and in a better understanding of the conceptual domain. It is also beneficial for performance in cognitive tasks (Calori et al. 1994). Team-dating teams develop more complex and at the same time more accurate representations concerning a conceptual domain than attribute-based teams, reflecting in-depth information processing and an ultimately higher chance of being successful in performing a cognitive task.

\section{Limitations and future research directions}

Several limitations should be kept in mind when interpreting the results of our study. First of all, even though we used causal reasoning throughout the paper, we only explored the role of team diversity as variety and reciprocal relational preferences for teamwork quality and teams' cognitive complexity. Team diversity and reciprocal relational preferences are indeed illustrative for the human and social capital within teams, which are important factors related to team performance (Harrison and Klein 2007; Van Knippenberg et al. 2004), but they are not the only ones. Other factors like motivation to work within a team 
(Van Knippenberg et al. 2004), task characteristics (Gladstein 1984), leadership (Bono and Ilies 2006), team structure (Stewart and Barrick 2000) or team context (Hackman 1990) are also relevant factors in team performance. Especially, in order to fully test the hypothesis that relational data are superior to attribute data in team design strategies, further investigations are needed, taking into account the above-mentioned factors.

Second, and in the same line of reasoning, variability of the structural characteristics of the networks, based on which the team-dating groups were created, were not controlled for in this study. One important assumption is that the variability of the team-dating teams with respect to the expressed preferences is constant. This assumption is, however, not completely fulfilled since the structural characteristics of the preference networks are different (see for example Figure 1). The research design and the sample size made it impossible to control for this factor. Consequently, further research is needed in order to understand the way in which the structural characteristics of the initial network of preferences affect team dynamics and team effectiveness.

Third, the structure of the cognitive mapping task is a boundary condition for our findings. The participants were explicitly asked to reach consensus while organizing the concepts. In modern organizations, consensus is not the universal way of dealing with group tasks. In some instances cliques or factions emerge in groups, and it is not unlikely that each of these cliques or factions will develop their own cognitive map regarding the task. This particular aspect was not explicitly addressed in our study and it is certainly one of the issues to be addressed in further research on team diversity and team cognition.

Finally, because we used a sample of students involved in two courses, there are a few limitations that need consideration. Although we performed the team dating at the beginning of the semester, we cannot be absolutely sure that all the students were perfect strangers to each other. Our results are only in part attributable to first impression formation. We see, therefore, two main directions to further develop this type of research. First, the question of whether relational data is indeed superior to attribute data in team formation processes should be tested in more controlled settings (laboratory studies). Second, the results of this study should be replicated in other organizational settings. This should provide ecological support for using relational data to design effective teams in a variety of contexts.

\section{Theoretical and practical implications}

We believe that the results have both practical and theoretical implications for the study of teams. The main practical implication refers to the possibility of using relational data collected from short initial contacts to create effective teams. Our results show that internal relational data are a sound premise for creating effective teams. This is a major contribution in the field of team management. Most of the previous studies on group effectiveness used a post hoc strategy of data collection and identified the factors related with team performance. Designing management strategies based on such factors is actually very difficult because the complex interdependencies among them are not yet clear (Van Knippenberg et al. 2004) and some factors are simply not open to manipulation 
(Reagans et al. 2004). In contrast, relational data are easy to collect and to use and are reliable predictors of team dynamics and effectiveness. This emphasizes again the role of socialization, in that it may not always be possible for managers to organize team-dating sessions when a team needs to be formed, but rather ask the employees directly about their work-related preferences. This assumes that employees have extensive interpersonal knowledge and they know each other sufficiently well. The team-dating procedure is especially suitable when the opportunities for interpersonal contacts and socialization among organizational members are limited.

Moreover, the method proposed can easily be applied in many different interas well as intra-organizational settings. It can be applied to create teams within organizations to accomplish complex tasks, implement restructuring processes, and foster innovation of new products or processes. But it can also be used to form inter-organizational teams, for example, when implementing the merger of two companies. In this setting, the method would imply organizing a speeddating session with all potential team members from both companies and subsequently selecting the cluster of persons with the most reciprocated ties involving an equal number of members from both companies as a side condition.

In other organizational settings, some additional issues might have to be considered when applying the speed-dating approach to team formation. First and foremost, it will rarely be possible to have every participant speak to every other participant because of time limitations and fatigue. Instead, for a given number of rounds, the dating pairs can be determined in a systematic way that ensures good mixing and eases evaluation. There are also degrees of freedom in the way that participants are asked for feedback, e.g. limits on the number of positive and negative choices or response scales. Depending on the type of response requested from participants, different clustering procedures may be appropriate. In particular, it is possible to deliberately build teams of varying quality with respect to interpersonal congruence. While we have already identified a number of criteria and solutions for different settings, the design and evaluation of more practical team-dating sessions, contact graph design and evaluation are beyond the scope of this paper.

From a theoretical perspective this study contributes to two streams of research: team diversity and network theory in team research. The empirical results reported in our study tested some of the theoretical propositions advanced by Van Knippenberg et al. (2004) in their integrative CEM theory and Harrison and Klein (2007) in their new group diversity taxonomy. The first contribution refers to the positive impact of variety on teams' cognitive complexity; this offers further empirical support for the beneficial effects of team variety on knowledge integration and team outcomes. The second contribution refers to the use of network theory as a team design tool and not only as a post-hoc formalism to explain team dynamics. As mentioned by Katz et al. (2004), because in most studies network data are collected after teams have produced outputs, it is not really possible to clearly state the position of the network in the causal chain. In our case, all relational data were collected prior to team development and this shed some light on the position of relational data on the causal chain of team performance. As mentioned before, this particular aspect needs further attention and research but it is an important step in using network theory in team research. 


\section{References}

Ambady, Nalini, and Rosenthal, Robert

1992 'Thin slices of expressive behavior as predictors of interpersonal consequences: A meta-analysis'. Psychological Bulletin 111/2: 256-274.

Ambady, Nalini, and Rosenthal, Robert

1993 'Half a minute: Predicting teacher evaluations from thin slices of nonverbal behavior and physical attractiveness'. Journal of Personality and Social Psychology 64/3: 431-441.

Ambady, Nalini, Hallahan, Mark, and Conner, Brett

1999 'Accuracy of judgments of sexual orientation from thin slices of behavior'. Journal of Personality and Social Psychology 77/3: 538-547.

Asch, Solomon Elliot

1946 'Forming impressions of personality'. Journal of Abnormal and Social Psychology 41: 1230-1240.

Bar-Tal, Daniel

1990 Group beliefs: A conception for analyzing group structure, processes and behavior. New York: SpringerVerlag.

Benders, Jos, Huijgen, Fred, and Pekruhl, Ulrich

2002 'What do we know about the incidence of group work (if anything)?' Personnel Review 31/3: 371-385.

Blanchard, Chris, Poon, Pauline, Rodgers, Wendy, and Pinel, Bruce

2000 'Group Environment Questionnaire and its applicability in an exercise setting'. Small Group Research 31/2: 210-224.

Bogenrieder, Irma, and Nooteboom, Bart

2004 'Learning groups: What types are there? A theoretical analysis and an empirical study in a consultancy firm'. Organization Studies 25: 287-313.

Bono, Joyce E., and Ilies, Remus

2006 'Charisma, positive emotions and mood contagion'. The Leadership Quarterly 17: 317-334.

Borkenau, Peter, Mauer, Nadine, Riemann, Rainer, Spinath, Frank M., and Angleitner, Alais

2004 'Thin slices of behavior as cues of personality and intelligence'. Journal of Personality and Social Psychology 86/4: 599-614
Bougon, Michel $\mathrm{G}$.

1992 'Congregate cognitive maps: A unified dynamic theory of organization and strategy'. Journal of Management Studies 29/3: 369-389.

Brandes, Ulrik, Gaertler, Marco, and Wagner, Dorothea

2003 'Experiments on graph clustering algorithms'. Proc. 11th Europ. Symp. Algorithms (ESA '03), Lecture Notes in Computer Science 2832: 568-579. New York: Springer-Verlag.

Calori, Ronald, Johnson, Gerry, and Sarnin, Philippe

1994 'CEO's cognitive maps and the scope of the organization'. Strategic Management Journal 15: 437-457.

Carroll, John S., Hatakenaka, Sachi, and Rudolph, Jenny W.

2006 'Naturalistic decision making and organizational learning in nuclear power plants: Negotiating meaning between managers and problem investigation teams'. Organization Studies 27: 1037-1057.

Carron, Albert V., and Brawley, Lawrence R.

2000 'Cohesion: Conceptual and measurement issues'. Small Group Research 31/1: 89-107.

Carron, Albert V., Widmeyer, Neil, W., and Brawley, Lawrence R.

1985 'The development of an instrument to assess cohesion in sport teams: The Group Environment Questionnaire'. Journal of Sport Psychology 7: 244-266.

Cummings, Jonathon N., and Cross, Rob

2003 'Structural properties of work groups and their consequences for performance'. Social Networks 25: 197-281.

Curşeu, Petru Lucian

2006 'Emergent states in virtual teams: A complex adaptive systems perspective'. Journal of Information Technology 21/4: 249-261.

Curşeu, Petru Lucian, Schalk, Rene, and Schruijer, Sandra G. L.(2010)

'The use of cognitive mapping in eliciting and evaluating group cognitions'. Journal of Applied Social Psychology 40/5: 1258-1291.

Curşeu, Petru Lucian, Schalk, Rene, and Wessel, Inge

2008 'How do virtual teams process information? A literature review and implications for management'. 
Journal of Managerial Psychology 23/6: 628-652.

Curşeu, Petıu Lucian, Schruijer, Sandra G. L., and Boroş, Smaranda

2007 'The effects of groups' variety and disparity on groups' cognitive complexity'. Group Dynamics: Theory, Research and Practice 11/3: 187-206.

Devine, Denis L., Clayton, Laura, Philis, Jennifer L., Dunford, Benjamin B., and Melner, Sarah B.

1999 'Teams in organizations: Prevalence, characteristics, and effectiveness' Small Group Research 30/6: 678-711.

Eby, Lillian T., Meade, Adam W., Parisi, Anthony G., and Douthitt, Shane S.

1999 'The development of an individuallevel teamwork expectations measure and the application of a within-group agreement statistic to assess shared expectations for teamwork'. Organizational Research Methods 2/4: 366-394.

Fiske, Susan T., and Taylor, Shelley E. 1991 Social cognition (2nd edn). New York: McGraw-Hill.

Gaertler, Marco

2005 'Clustering' in Network analysis Methodological foundations (Lecture Notes in Computer Science 3418). U. Brandes and T. Erlebach (eds), 178-215. Berlin: Springer-Verlag.

Gladstein, Deborah

1984 'Groups in context: A model of task group effectiveness'. Administrative Science Quarterly 29: 499-518.

Gómez, A., Moreno, Ana Maria, Pazos, Juan, and Sierra-Alonso, Almudena

2000 'Knowledge maps: An essential technique for conceptualization'.

Data and Knowledge Engineering 33: 169-190.

Gully, Stanley M., Incalcatera, Kara A., Joshi, Aparna, and Beaubien, Mathieu J.

2002 'A meta-analysis of team-efficiency, potency and performance: Interdependence and level of analysis as moderators of observed relationships'. Journal of Applied Psychology 87/5: 819-832.

Guzzo, Richard A., and Dickson, Markus W.

1996 'Team in organizations: Recent research on performance and effectiveness'. Annual Review of Psychology 47: 307-338.
Guzzo, Richard A., Yost, Paul R., Campbell, Richard J., and Shea, Gregory P.

1993 'Potency in groups: Articulating a construct'. British Journal of Social Psychology 32: 87-106.

Hackman, Richard J.

1990 Groups that work (and those that don't). San Francisco: Jossey-Bass.

Hambrick, Donald C., Davison, Sue Canney, Snell, Scott A., and Snow, Charles C.

1998 'When groups consist of multiple nationalities: Toward a new understanding of the implications'. Organization Studies 19: 181-205.

Harrison, David A., and Klein, Katherine J.

2007 'What's the difference? Diversity constructs as separation, variety, or disparity in organizations'. Academy of Management Review 32/4: 1199-1228.

Hinds, Pamela J., Carley, Kathleen M., Krackhardt, David, and Wholey, Doug

2000 'Choosing work group members: Balancing similarity, competence, and familiarity'. Organizational Behavior and Human Decision Processes 81/2: 226-251.

Hinsz, Verlin B., Tindale, Scott, R., and Vollrath, David A.

1997 'The emerging conceptualization of groups as information processors'. Psychological Bulletin 121/1: 43-64.

Hodgkinson, Gerard P., and Healey, Mark P.

2008 'Toward a (pragmatic) science of strategic intervention: Design propositions for scenario planning'. Organization Studies 29: 435-457.

Hoegl, Martin, and Gemuenden, Hans G.

2001 'Teamwork quality and the success of innovative projects: A theoretical concept and empirical evidence'. Organization Science 12/4: 435-449.

Ilgen, Daniel R., Hollenbeck, John R., Johnson, Michael, and Jundt, Dustin

2005 'Team in organizations: From InputProcess-Output models to IMOI models'. Annual Review of Psychology 56: 517-543.

Jelinek, Mariann, Romme, Georges A. L., and Boland, Richard J.

2008 'Introduction to the special issue Organization Studies as a Science for Design: Creating collaborative artifacts and research'. Organization Studies 29: 317-329.

Jehn, Karen A., and Shah, Priti P.

1997 'Interpersonal relationships and task 
performance: An examination of mediating processes in friendship and acquaintance groups'. Journal of Personality and Social Psychology 72: 775-790.

Jones, Edward E.

1990 Interpersonal perception. New York: W. H. Freeman and Co.

Karau, Stevens J., and Williams, Kipling D.

1993 'Social loafing: A meta-analytic review and theoretical integration'. Journal of Personality and Social Psychology 65: 681-706.

Katz, Nancy, Lazer, David, Arrow, Holly, and Contractor, Noshir

2004 'Network theory and small groups'. Small Group Research 35/3: 307-332.

Kirkman, Bradley L., Tesluk, Paul E., and Rosen, Benson

2001 'Alternative methods of assessing team-level variables: Comparing the predictive power of aggregation and consensus methods'. Personnel Psychology 54: 645-667.

Krackhardt, David, and Stern, Robert N.

1988 'Informal networks and organizational crises: An experimental simulation'. Social Psychology Quarterly 51/2: 123-140.

Marks, Michelle A., Mathieu, John E., and Zaccaro, Stephen J.

2001 'A temporally based framework and taxonomy of team processes'. Academy of Management Review 26/3: 356-376.

Minssen, Heiner

2005 'Challenges of teamwork in production: Demands on communication'. Organization Studies 27: 103-124.

Oh, Hongseok S., Chung, Myung-Ho, and Labianca, Giuseppe

2004 'Group social capital and group effectiveness: The role of informal socializing ties'. Academy of Management Journal 47/6: 860-875.

Okhuysen, Gerardo A., and Eisenhardt, Kathleen $M$.

2002 'Integrating knowledge in groups: How do formal interventions enable flexibility?'. Organization Science 13/4: 370-386.

Polzer, Jeffrey T., Milton, Laurie P., and Swann, William B.

2002 "Capitalizing on diversity: Interpersonal congruence in small work groups'. Administrative Science Quarterly 47: 296-324.

Reagans, Ray, and Zuckerman, Ezra

2001 'Networks, diversity, and productivity: The social capital of corporate R\&D teams'. Organization Science 12/4: 502-517.

Reagans, Ray, Zuckerman, Ezra, and McEvily, Bill

2004 'How to make a team: Social networks vs. demography as criteria for designing effective teams'. Administrative Science Quarterly 49: 101-133.

Rentsch, Joan R., and Wochr, David J.

2004 'Quantifying congruence in cognitions: Social relations modeling and team member schema similarity' in Team cognition: Understanding the factors that drive process and performance. E. Salas and S. M. Fiore (eds), 11-31. Washington, DC: American Psychological Association.

Romme, Georges A. L.

2003 'Organizing education by drawing on organization studies'. Organization Studies 24: 697-720.

Shah, Priti, and Jehn, Karen A.

1993 'Do friends perform better than acquaintances? The interaction of friendship, conflict, and task'. Group Decision and Negotiation 2: 149-165.

Stewart, Greg L.

2006 'A meta-analytic review of relationship between team design features and team performance'. Journal of Management 32/1: 29-54.

Stewart, Greg L., and Barrick, Murray R.

2000 'Team structure and performance: Assessing the mediating role of intrateam process and the moderating role of task type'. Academy of Management Journal 43/2: 135-148.

Stewart, Ralph $\mathrm{H}$.

1965 'Effect of continuous responding on the order effect in personality impression formation'. Journal of Personality and Social Psychology 1: 161-165.

Strang, David, and Jung, Dong-II

2009 'Participatory improvement at a global bank: The diffusion of quality teams and the demise of a six sigma initiative'. Organization Studies 30: 31-53.

Sunnafrank, Michael, and Ramirez, Artemio Jr. 2004 'At first sight: Persistent relational 
effects of get-acquainted conversations'. Journal of Social and Personal Relationships 21/3: $361-379$

Swann, William B. Jr., Milton, Laurie P., and Polzer, Jeffrey T.

2000 'Should we create a niche or fall in line? Identity negotiation and small group effectiveness'. Journal of Personality and Social Psychology 79: 238-250.

Swann, William B. Jr., Kwan, Virginia S. Y., Polzer, Jeffrey T., and Milton, Laurie P.

2003 'Fostering group identification and creativity in diverse groups: The role of individuation and selfverification'. Personality and Social Psychology Bulletin 29/11: 1396-1406.

Swann, William B. Jr, Polzer, Jeffrey T., Seyle, Connor, Daniel, and Ko, Seijin J.

2004 'Finding value in diversity: Verification of personal and social self views in diverse groups'. Academy of Management Review 29/1: 9-27.

Teachman, Jay D.

1980 'Analysis of population diversity'.
Sociological Methods and Research 5/3: 341-362.

Van Knippenberg, Daan, De Dreu, Carsten K. W., and Homan, Astrid C.

2004 'Work group diversity and group performance: An integrative model and research agenda'. Journal of Applied Psychology 89/6: 1008-1022.

Vera, Dusya, and Crossan, Mary

2004 'Theatrical improvisation: Lessons for organizations'. Organization Studies. 25: 727-749.

Williams, Helen M., and Meân, Lindsey J.

2004 'Measuring gender composition in work groups: A comparison of existing methods'. Organizational Research Methods 7/4: 456-474.

Williams, Katherine Y., and O'Reilly, Charles A. 1998 'Demography and diversity in organizations: A review of 40 years of research'. Research in Organizational Behavior 20: 77-140.

Zárraga, Celia, and Bonache, Jaime

2005 'The impact of team atmosphere on knowledge outcomes in self-managed teams'. Organization Studies 26: 661-681.
Petru L. Curşeu

\section{Patrick Kenis}

Jörg Raab
Petru L. Curşeu is Associate Professor of Organizational Behavior at the Department of Organization Studies at Tilburg University, and he teaches courses on Organizational Behavior and Complexity within Organizations. He received his $\mathrm{PhD}$ from Tilburg University and his research interests include team dynamics (with a special focus on team cognition), social cognition (in particular the study of stereotypes and prejudice in organizational settings), as well as decision-making in organizations. He has published papers on related topics in Journal of Information Technology, European Journal of Social Psychology, Group Dynamics, Journal of Managerial Psychology, Studia Psychologica and other journals.

Address: Department of Organization Studies, Tilburg University, Room P 1.161; Warandelaan 2, PO Box 90153, 5000 LE Tilburg, The Netherlands.

Email: P.L.Curseu@uvt.nl

Patrick Kenis is academic dean at TiasNimbas Business School and Professor of Policy and Organizations Studies at the Department of Organization Studies, Tilburg University. He holds an MPhil from the Free University of Brussels (Belgium) and a PhD from the European University Institute (Florence, Italy). He has published in journals including the Academy of Management Review, International Public Management Journal, Journal of Theoretical Politics, Journal of Public Administration Research and Theory, Journal of Management Inquiry plus a number of (co-)authored book chapters and books. His current research interests involve temporary organizations, organizational networks, and internet communities.

Jörg Raab is Assistant Professor of Policy and Organization Studies at the Department of Organization Studies, Tilburg University. He received his $\mathrm{PhD}$ from the University of Konstanz/Germany. His research focuses mainly on (interorganizational) networks and 
public organizations as well as on governance mechanisms in the state, economy and society. He has published in journals including the International Public Management Journal, Journal of Theoretical Politics, Journal of Public Administration Research and Theory, Journal of Management Inquiry plus a number of (co)authored book chapters and books. His current research interests involve temporary organizations, organizational networks, and dark networks as organizational problems.

Ulrik Brandes Ulrik Brandes is Professor of Computer Science at the University of Konstanz, Germany. He received a $\mathrm{PhD}$ in computer science in 1999 and completed his habilitation at the University of Konstanz in 2002. From 2002 to 2003 he was an Associate Professor of Computer Science at the University of Passau, Germany. His specializes in algorithmics, in particular graph algorithms for network analysis and visualization, and social networks. He is associate editor of the journal Social Networks, editorial board member of the Journal of Graph Algorithms and Applications, and board member of the International Network of Social Network Analysis. 